\title{
The efficacy of thoracoscopic fissureless lobectomy in patients with dense fissures
}

\author{
Hitoshi Igai ${ }^{1}$, Mitsuhiro Kamiyoshihara ${ }^{1}$, Ryohei Yoshikawa ${ }^{1}$, Fumi Osawa ${ }^{1}$, Natsuko Kawatani ${ }^{1}$, Takashi Ibe ${ }^{1}$, \\ Kimihiro Shimizu ${ }^{2}$ \\ ${ }^{1}$ Department of General Thoracic Surgery, Maebashi Red Cross Hospital, Maebashi, Japan; ${ }^{2}$ Department of Thoracic and Visceral Organ Surgery, \\ Gunma University Graduate School of Medicine, Maebashi, Japan \\ Contributions: (I) Conception and design: H Igai, M Kamiyoshihara; (II) Administrative support: H Igai, M Kamiyoshihara; (III) Provision of study \\ materials or patients: H Igai, M Kamiyoshihara; (IV) Collection and assembly of data: H Igai, N Kawatani; (V) Data analysis and interpretation: H \\ Igai, M Kamiyoshihara; (VI) Manuscript writing: All authors; (VII) Final approval of manuscript: All authors. \\ Correspondence to: Hitoshi Igai, MD, PhD. Department of General Thoracic Surgery, Maebashi Red Cross Hospital, 3-21-36 Asahi-cho, Maebashi, \\ Gunma 371-0014, Japan. Email: hitoshi-iga@hotmail.co.jp.
}

Background: Prolonged air leakage after a lobectomy remains a frequent complication in patients with dense fissures. To avoid postoperative air leakage, we used the "thoracoscopic fissureless technique" for patients with dense fissures. A thoracoscopic approach is useful for the fissureless technique because it gives a good operative view from various angles without dividing the fissure. In this study, we compared the perior intraoperative results of thoracoscopic fissureless lobectomies to traditional lobectomies with fissure dissection for pulmonary artery (PA) exposure in order to identify the efficacy of thoracoscopic fissureless lobectomy.

Methods: Between April 2012 and November 2015, 175 patients underwent a thoracoscopic lobectomy with three or four ports, of whom 14 underwent a fissureless lobectomy because of dense fissures. We compared the characteristics and perioperative outcomes of the patients who underwent the fissureless technique (fissureless technique group, $\mathrm{n}=14$ ) and the traditional fissure dissection technique for PA exposure (traditional technique group, $\mathrm{n}=161$ ). In our department, fissureless lobectomy is indicated for patients with a fused fissure (fissural grade III or IV as proposed by Craig in 1997) or inflammation makes it difficult to expose the PA, while the traditional technique is used for other patients.

Results: Although the fissureless technique group had longer operation time than the traditional technique group ( $\mathrm{P}=0.0045)$, there was no significant inter-group difference about blood loss $(\mathrm{P}=0.85)$, occurrence rate of intraoperative massive bleeding $(\mathrm{P}=0.6)$ or conversion rate to thoracotomy $(\mathrm{P}=0.31)$. According to postoperative results, there was no significant inter-group difference in duration of chest tube drainage $(\mathrm{P}=0.56)$, length of postoperative hospital stay $(\mathrm{P}=0.14)$, or morbidity rate $(\mathrm{P}=0.16)$. No mortality occurred in either group.

Conclusions: A thoracoscopic fissureless lobectomy is feasible and safe, and useful to avoid postoperative air-leakage in patients with dense fissures.

Keywords: Troubleshooting; bleeding; thoracoscopy; pulmonary resection

Submitted Aug 28, 2016. Accepted for publication Nov 15, 2016.

doi: $10.21037 /$ jtd.2016.12.58

View this article at: http://dx.doi.org/10.21037/jtd.2016.12.58 


\section{Introduction}

The incidence of prolonged air leak (PAL) is a common complication after pulmonary major surgeries, which incidences reported $7.6-10 \%$ in several studies (1-4).

Although many intraoperative methods have been reported for general thoracic surgeries, including the use of surgical sealants or stapler line buttress materials to avoid postoperative air leakage, none of them has been shown to have clear benefits or universal applicability $(5,6)$. In addition, it is also considered to be unclear whether perioperative managements including water seal management or digital drainage system after a pulmonary lobectomy reduces the incidence of PAL or not (7-9).

PAL after a lobectomy frequently occurs especially in patients with dense fissures. For these patients with dense fissures, we use the "thoracoscopic fissureless technique" to avoid postoperative PAL. Although there have been several reports demonstrating the efficacy of fissureless lobectomy to avoid postoperative PAL, most of these reports demonstrated only right upper fissureless lobectomies because the fissure between a right upper and a middle lobe is frequently fused compared with other fissures $(10,11)$. And, Gómez-Caro et al. and Nomori et al. reported that the efficacy of fissureless technique in any type of lobectomy, however, their approach was via mini-thoracotomy or thoracotomy $(12,13)$. To our best knowledge, there has been an only report demonstrating the efficacy of thoracoscopic fissureless lobectomy by Stamenovic and colleagues (14). Compared to a thoracotomy or a mini-thoracotomy approach, a thoracoscopic approach might be useful for the fissureless technique because it gives a good operative view from various angles without dividing the fissure (15).

In this study, we compared the peri- or intraoperative results of thoracoscopic fissureless lobectomies to those of traditional lobectomies with fissure dissection for pulmonary artery (PA) exposure in order to identify the efficacy of thoracoscopic fissureless lobectomy, and herein report the results.

\section{Methods}

\section{Patients}

Between April 2012 and November 2015, 175 patients underwent a thoracoscopic lobectomy with three or four ports, of whom 14 underwent a fissureless lobectomy because of dense fissures. We compared the characteristics and perioperative outcomes of the patients who underwent the fissureless technique (fissureless technique group, $\mathrm{n}=14$ ) and the traditional fissure dissection technique for PA exposure (traditional technique group, $\mathrm{n}=161$ ).

\section{Fissural grade}

In our department, the fissureless lobectomy is applied for patients with a fused fissure (fissural grade III or IV as proposed by Craig in 1997) or inflammation makes it difficult to expose the PA, while the traditional technique is used for other patients (16).

\section{Surgical technique}

\section{General remarks}

Thoracoscopic lobectomies were performed under general anesthesia using one-lung ventilation with the patient in the lateral decubitus position. We used a 5- or 10-mm flexibletype thoracoscope in any case. While the assistant surgeon in a dorsal position, the operating surgeon stood ventral to the patient.

A television monitor was placed above the head of the patient. All procedures were performed by using thoracoscopic vision. The access incision (initially, $3 \mathrm{~cm}$ in length) was placed at 4th or 5th intercostal space on the anterior axillary line. At the 6th or 7th intercostal space on the posterior axillary line, the thoracoscopic port was placed. One additional port was placed at the 6 th intercostal space on the anterior axillary line. These ports were covered with an XXS size wound retractor (Alexis Wound Retractor, Applied Medical, Rancho Santa Margarita, CA, USA), and the access port with an XXS or an XS size retractor. In any lobectomy, the dense interlobar fissure is finally divided by staplers. On completion of the pulmonary resection, the specimen was placed into an endovascular bag and retrieved through the access port. If necessary, the incision was enlarged to a length of $4-5 \mathrm{~cm}$, depending on the specimen size. A rib-spreader was never used at any point during the operation. A drainage tube was placed in the thorax through the 6 th intercostal port on the anterior axillary line at the end of operation.

\section{Right upper lobectomy}

Figure 1 demonstrates the procedure of thoracoscopic fissureless right upper lobectomy.

While the upper lobe is retracted towards the back, the upper lobe vein and the anterior PA trunk to the upper lobe are exposed and divided. After the division of right upper 


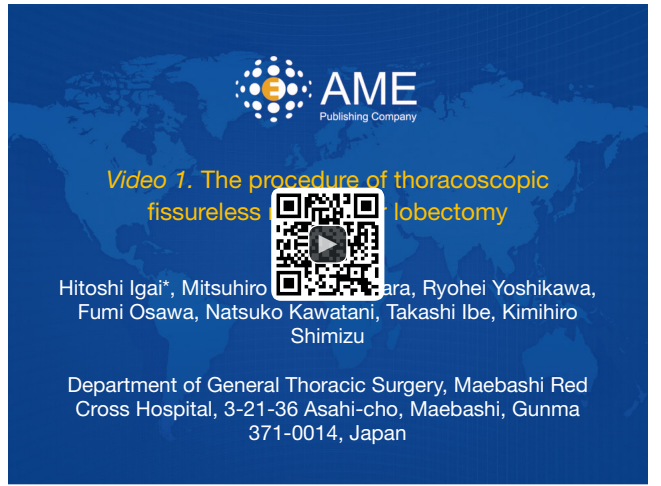

Figure 1 The procedure of thoracoscopic fissureless right upper lobectomy (17). While the upper lobe is retracted towards the back, the upper lobe vein is exposed and divided by a stapler. And then, anterior pulmonary artery (PA) trunk to the upper lobe is exposed and divided by a stapler in the same manner. After the division of right upper lobe (RUL) bronchus by a stapler, the ascending artery is divided. Finally, the dense interlobar fissure is divided by staplers. Available online: http://www.asvide.com/articles/1305

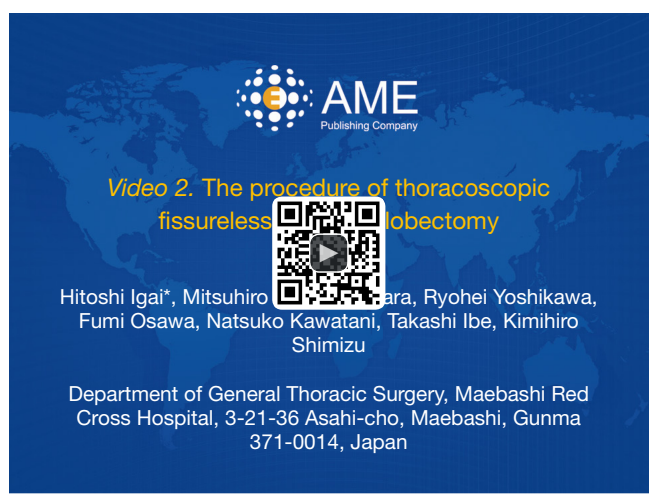

Figure 2 The procedure of thoracoscopic fissureless left lower lobectomy (18). At first, pulmonary ligament is incised up to inferior pulmonary vein (IPV) while the lower lobe is retracted towards the head. And then, the sheath of pulmonary artery (PA) is dissected. IPV is exposed and divided by a stapler. And, the lower bronchus is dissected and divided by a stapler. The pulmonary arteries lay right behind the bronchus. We identify common basal and superior segmental arteries, and then divide each. Finally, the dense interlobar fissure is divided by staplers. Available online: http://www.asvide.com/articles/1306

lobe (RUL) bronchus by a stapler, the ascending artery is divided. However, it is better to dissect and divide the ascending $\mathrm{A}^{2}$ prior to RUL bronchus when the ascending $\mathrm{A}^{2}$ branches from a comparatively proximal portion.

\section{Right middle lobectomy}

While the middle and the lower lobe are retracted towards the back, the middle lobe vein and the bronchus are divided by a stapler. The middle lower PA lies right behind the bronchus, and is divided.

\section{Right or left lower lobectomy}

The inferior pulmonary vein (IPV) and the lower bronchus are divided after dissection of the pulmonary ligament while the lower lobe is retracted towards the head. The pulmonary arteries lay right behind the bronchus. We should identify common basal and superior segmental arteries, and then divide each. Prior to the division of lower bronchus, the sheath of pulmonary arteries should be dissected. This procedure will avoid the injury of the branches of the cranial PA.

\section{Left upper lobectomy}

While the upper lobe is retracted towards the back, the superior PV is divided. And then, the anterior segmental $\mathrm{PA}$ is divided by a stapler. After the division of left upper lobe (LUL) bronchus by a stapler, the lingual segmental pulmonary arteries are exposed and divided. And then, the apicoposterior segmental arteries are finally exposed and divided while the upper lobe is retracted towards the abdomen.

We demonstrate a right upper lobectomy and a left lower lobectomy in the attached video (Figures 1,2).

\section{Postoperative management}

Thoracic drainage started with a suction or a single chamber water seal used simple gravity, depending on the patients, after the operation.

The chest tube was removed at the time when air-leakage disappeared or total volume of pleural effusion became under $300 \mathrm{~mL} /$ day on postoperative day 2 or later.

In cases that persistent air-leakage lasted longer than 4 days, postoperative pleurodesis was performed.

\section{Statistical analysis}

Statistical analyses were performed using independent $t$-test or Fisher's exact test for comparison of perioperative results. Differences were considered significant at $\mathrm{P}<0.05$. Calculations and statistical tests were performed using the Statview 5.0 software package (SAS Institute, Inc., Cary, NC, USA). 


\section{Results}

Table 1 demonstrates the list of diseases in the fissureless technique group. Eight patients with primary lung cancers are composed of cT3N0M0 (pT3N0M0) in 3, cT2bN1M0 (pT2bN1M0) in 1, cT2aN0M0 (pT2aN1M0) in 1, cT2aN0M0 (pT2aN0M0) in 1, cT1bN0M0 (pT1bN0M0) in 1 , and cT1aN0M0 (pT1aN0M0) in 1.

Table 1 The list of diseases in the fissureless technique group

\begin{tabular}{lc}
\hline Disease & The number of patients $(\%)$ \\
\hline Primary lung cancer & $8(57.1)$ \\
Metastatic lung cancer & $3(21.4)$ \\
Inflammatory disease & $2(14.3)$ \\
Trauma & $1(7.1)$ \\
\hline
\end{tabular}

Table 2 The ratio of each lobectomy in the fissureless technique group $(n=14)$ and the traditional technique group $(n=161)$

\begin{tabular}{lll}
\hline Variable & $\begin{array}{c}\text { Fissureless technique, } \\
\mathrm{n}=14(\%)\end{array}$ & $\begin{array}{c}\text { Traditional technique, } \\
\mathrm{n}=161(\%)\end{array}$ \\
\hline Resected lobe & & $47(29.2)$ \\
RUL & $5(35.7)$ & $10(6.2)$ \\
RML & $4(28.6)$ & $25(15.5)$ \\
RLL & $1(7.1)$ & $41(25.5)$ \\
LUL & $0(0)$ & $38(23.6)$ \\
LLL & $4(28.6)$ &
\end{tabular}

RUL, right upper lobe; RML, right middle lobe; RLL, right lower lobe; LUL, left upper lobe; LLL, left lower lobe.
Table 2 demonstrates the ratio of each lobectomy in the two groups.

Table 3 lists the patients' characteristics and perioperative results in the two groups.

Although the fissureless technique group had longer operation time than the traditional technique group (fissureless technique group: $270 \pm 49$ min vs. traditional technique group: $222 \pm 60 \mathrm{~min}, \mathrm{P}=0.0045)$, there was no significant inter-group difference about blood loss (fissureless technique group: $80 \pm 70 \mathrm{~mL} v s$. traditional technique group: $90 \pm 195 \mathrm{~mL}, \mathrm{P}=0.85$ ), occurrence rate of intraoperative massive bleeding (fissureless technique group: $1,7.1 \%$ vs. traditional technique group: $19,11.8 \%, \mathrm{P}=0.6$ ) or conversion rate to thoracotomy (fissureless technique group: $0,0 \%$ vs. traditional technique group: $11,6.8 \%$, $\mathrm{P}=0.31$ ). According to postoperative results, there was no significant inter-group difference in duration of chest tube drainage (fissureless technique group: $3.9 \pm 1.9$ days $v$ s. traditional technique group: $3.5 \pm 2.6$ days, $\mathrm{P}=0.56$ ), length of postoperative hospital stay (fissureless technique group: $15.4 \pm 20.5$ days $v s$. traditional technique group: $9.2 \pm 14.5$ days, $\mathrm{P}=0.14$ ), or morbidity rate (fissureless technique group: 5 , $35.7 \%$ vs. traditional technique group: $32,20 \%, \mathrm{P}=0.16$ ). No mortality occurred in either group.

\section{Discussion}

Several authors have reported the efficacy of fissureless lobectomy since Temes and colleagues first reported fissureless lobectomy as a procedure to avoid postoperative PAL (19). A trial conducted by Gómez-Caro et al.

Table 3 The characteristics and perioperative outcomes in the fissureless technique group $(n=14)$ and the traditional technique group ( $\mathrm{n}=161)$

\begin{tabular}{lccc}
\hline Variable & Fissureless technique, $\mathrm{n}=14(\%)$ & Traditional technique, $\mathrm{n}=161(\%)$ & $\mathrm{P}$ value \\
\hline Age (years) & $67 \pm 16$ & $70 \pm 9$ & 0.23 \\
Gender $(\mathrm{n})$ & & & 0.52 \\
$\quad$ Male & $10(71.4)$ & $101(62.7)$ & \\
Female & $4(28.6)$ & $60(37.3)$ & 0.0045 \\
Operation time (min) & $270 \pm 49$ & $222 \pm 60$ & 0.85 \\
Blood loss (mL) & $80 \pm 70$ & $90 \pm 195$ & 0.60 \\
Intraoperative massive bleeding (n) & $1(7.1)$ & $19(11.8)$ & 0.31 \\
Conversion to thoracotomy $(\mathrm{n})$ & $0(0)$ & $11(6.8)$ & 0.56 \\
Duration of chest tube drainage (days) & $3.9 \pm 1.9$ & $3.5 \pm 2.6$ & 0.14 \\
Length of postoperative hospital stay (days) & $15.4 \pm 20.5$ & $9.2 \pm 14.5$ & 0.16 \\
Morbidity $(\mathrm{n})$ & $5(35.7)$ & $32(20.0)$ & \\
\hline
\end{tabular}


demonstrated that the use of a fissureless technique significantly reduced the incidence and duration of air leakage (12). Similarly, $\mathrm{Ng}$ et al. found that the use of a fissureless technique reduced the duration of chest tube drainage and shortened the length of hospital stay (11). In Stamenovic's report studying thoracoscopic fissureless lobectomy prospectively, the thoracoscopic fissureless lobectomy group was also significantly superior to the conventional thoracoscopic lobectomy group about the occurrence rate of PAL, the duration of chest tube drainage or the length of hospital stay (14). Therefore, Stamenovic and colleagues concluded that a thoracoscopic fissureless lobectomy appears to be a superior technique to conventional thoracoscopic lobectomy in terms of preventing PAL and reducing the length of hospital stay. And, there was no significant difference about operation time in Stamenovic's report.

In our study, operation time in fissureless lobectomy group was longer than that in traditional lobectomy group although there was no significant difference between the two groups in any other parameter including duration of chest tube drainage and length of postoperative hospital stay. In the patients' population of our study, the fissureless lobectomy group was composed of only the patients with fused fissure, while the traditional lobectomy group was composed of the patients with completely or almost divided fissure. The patients with fused fissure are likely to have pulmonary comorbidities including chronic obstructive lung disease, interstitial pneumonia, or intrathoracic adhesion. For these patients, we usually have some difficulties in performing surgery or treating postoperative care. We speculate these difficulties of the patients in the fissureless technique group led the longer operation time than that in the traditional technique group. In addition, we were unfamiliar with fissureless techniques in a totally thoracoscopic approach even if we were familiar with a fissureless lobectomy in thoracotomy approach. We consider this unfamiliarity is another reason why the fissureless technique group had the longer operation time.

Regarding duration of chest tube drainage, this study does not demonstrate the superiority of fissureless lobectomy while previous studies showed that a fissureless technique is superior to a traditional technique about the occurrence rate of PAL. We consider that this result was caused by the bias of patients' fissural grade. Therefore, it might be valid this study demonstrates the non-inferiority of fissureless technique about the avoidance of PAL even if any patients in the fissureless technique group had dense fissures while any patients in the traditional technique group had no dense fissures.

In fissureless lobectomies, dominant bronchus is usually resected prior to dominant pulmonary arteries. Therefore, the procedure sometimes seems to be not safe for the surgeons who are not familiar with it. Especially in either lower lobectomy, the PA that should be resected is located right behind lower bronchus, which potentially leads a catastrophic pulmonary arterial injury when the connective tissue between the lower bronchus and the PA is dissected. To avoid this pulmonary arterial injury, we usually dissect the sheath of the PA enough to proceed through the tissue between the lower bronchus and the PA smoothly for forceps or staplers. We consider this technique is most important to avoid the accidental injury of the PA in either lower lobectomy. In addition, this technique leads the sufficient dissection of lymph nodes around the bronchus. It is sometimes criticized that a fissureless lobectomy potentially causes insufficient lymph nodes dissection for malignant diseases. However, the bronchus can be almost separated from the PA by using this technique. Therefore, we consider that we can perform enough lymph nodes dissection for malignant diseases even in the fissureless lobectomy by using the technique that the sheath of the PA is dissected prior to division of the bronchus.

Although the patients who underwent thoracoscopic fissureless lobectomies had longer operating times, no significant differences were observed between the groups in the other perioperative results, including the duration of postoperative drainage. This study is limited by its retrospective character and selection bias of the patients. However, these non-inferior results might indicate that a thoracoscopic fissureless lobectomy is feasible and safe, and useful to avoid postoperative PAL in patients with dense fissures.

\section{Acknowledgements}

The authors appreciate the contributions of all the surgeons, coworkers who participated in this study, and thank the editors and reviewers for their help with this manuscript.

\section{Footnote}

Conflicts of Interest: The authors have no conflicts of interest to declare. 
Ethical Statement: The institutional review board of Maebashi Red Cross Hospital determined that this study was exempt from formal review.

\section{References}

1. Allen MS, Darling GE, Pechet TT, et al. Morbidity and mortality of major pulmonary resections in patients with early-stage lung cancer: initial results of the randomized, prospective ACOSOG Z0030 trial. Ann Thorac Surg 2006;81:1013-9; discussion 1019-20.

2. Droghetti A, Schiavini A, Muriana P, et al. A prospective randomized trial comparing completion technique of fissures for lobectomy: stapler versus precision dissection and sealant. J Thorac Cardiovasc Surg 2008;136:383-91.

3. Varela G, Jiménez MF, Novoa N, et al. Estimating hospital costs attributable to prolonged air leak in pulmonary lobectomy. Eur J Cardiothorac Surg 2005;27:329-33.

4. Orsini B, Baste JM, Gossot D, et al. Index of prolonged air leak score validation in case of video-assisted thoracoscopic surgery anatomical lung resection: results of a nationwide study based on the French national thoracic database, EPITHOR. Eur J Cardiothorac Surg 2015;48:608-11.

5. Miller JI Jr, Landreneau RJ, Wright CE, et al. A comparative study of buttressed versus nonbuttressed staple line in pulmonary resections. Ann Thorac Surg 2001;71:319-22; discussion 323.

6. Belda-Sanchís J, Serra-Mitjans M, Iglesias Sentis M, et al. Surgical sealant for preventing air leaks after pulmonary resections in patients with lung cancer. Cochrane Database Syst Rev 2010;(1):CD003051.

7. Brunelli A, Sabbatini A, Xiume' F, et al. Alternate suction reduces prolonged air leak after pulmonary lobectomy: a randomized comparison versus water seal. Ann Thorac Surg 2005;80:1052-5.

8. Alphonso N, Tan C, Utley M, et al. A prospective randomized controlled trial of suction versus non-suction to the under-water seal drains following lung resection. Eur J Cardiothorac Surg 2005;27:391-4.

Cite this article as: Igai $\mathrm{H}$, Kamiyoshihara $\mathrm{M}$, Yoshikawa $\mathrm{R}$, Osawa F, Kawatani N, Ibe T, Shimizu K. The efficacy of thoracoscopic fissureless lobectomy in patients with dense fissures. J Thorac Dis 2016;8(12):3691-3696. doi: 10.21037/ jtd.2016.12.58
9. Filosso PL, Nigra VA, Lanza G, et al. Digital versus traditional air leak evaluation after elective pulmonary resection: a prospective and comparative monoinstitutional study. J Thorac Dis 2015;7:1719-24.

10. Refai M, Brunelli A, Salati M, et al. Efficacy of anterior fissureless technique for right upper lobectomies: a casematched analysis. Eur J Cardiothorac Surg 2011;39:1043-6.

11. Ng T, Ryder BA, Machan JT, et al. Decreasing the incidence of prolonged air leak after right upper lobectomy with the anterior fissureless technique. J Thorac Cardiovasc Surg 2010;139:1007-11.

12. Gómez-Caro A, Calvo MJ, Lanzas JT, et al. The approach of fused fissures with fissureless technique decreases the incidence of persistent air leak after lobectomy. Eur J Cardiothorac Surg 2007;31:203-8.

13. Nomori H, Ohtsuka T, Horio H, et al. Thoracoscopic lobectomy for lung cancer with a largely fused fissure. Chest 2003;123:619-22.

14. Stamenovic D, Bostanci K, Messerschmidt A, et al. Fissureless fissure-last video-assisted thoracoscopic lobectomy for all lung lobes: a better alternative to decrease the incidence of prolonged air leak? Eur J Cardiothorac Surg 2016;50:118-23.

15. Igai $\mathrm{H}$, Kamiyoshihara $M$, Kawatani $\mathrm{N}$, et al. Thoracoscopic caudal left lower lobectomy in a patient with fused fissure. Asian J Endosc Surg 2014;7:342-4.

16. Craig SR, Walker WS. A proposed anatomical classification of the pulmonary fissures. J R Coll Surg Edinb 1997;42:233-4.

17. Igai H, Kamiyoshihara M, Yoshikawa R, et al. The procedure of thoracoscopic fissureless right upper lobectomy. Asvide 2016;3:530. Available online: http:// www.asvide.com/articles/1305

18. Igai H, Kamiyoshihara $M$, Yoshikawa R, et al. The procedure of thoracoscopic fissureless left lower lobectomy. Asvide 2016;3:531. Available online: http:// www.asvide.com/articles/1306

19. Temes RT, Willms CD, Endara SA, et al. Fissureless lobectomy. Ann Thorac Surg 1998;65:282-4. 